\title{
Evaluation of quantitative changes in regulatory T cells in peripheral blood of kidney transplant recipients with skin cancer after conversion to mTOR inhibitors
}

\author{
Agnieszka Cegielska, Katarzyna A. Lisowska², Alicja Dębska-Ślizieńn ${ }^{1}$, Beata Imko-Walczuk², \\ Aleksandra Okuniewska ${ }^{3,4}$, Bolesław Rutkowski ${ }^{1}$ \\ ${ }^{1}$ Department of Nephrology, Transplantology and Internal Medicine, Medical University of Gdansk, Gdansk, Poland \\ ${ }^{2}$ Department of Pathophysiology, Medical University of Gdansk, Gdansk, Poland \\ ${ }^{3}$ Copernicus - Independent Public Healthcare Centre - Dermatology and Venereology Clinic, Gdansk, Poland \\ ${ }^{4}$ Department of Medical Chemistry, Medical University of Gdansk, Gdansk, Poland
}

Adv Dermatol Allergol 2018; XXXV (5): 474-480

DOI: https://doi.org/10.5114/ada.2018.77237

\begin{abstract}
Introduction: Immunosuppressive therapy, necessary for graft survival, has its clinical consequences with an increased risk of developing malignancies being one of them. It seems that the maintenance of a proper balance between cytotoxic and regulatory activity of the immune system may prevent graft rejection, and with a lower risk of cancer.

Aim: To assess the quantitative changes in regulatory T cells (Tregs) in peripheral blood of kidney transplant recipients with post-transplantation skin neoplasm after conversion to mTOR inhibitors (mTORi) and to assess the incidence of secondary skin cancer in that group of patients.

Material and methods: Fourteen patients with post-transplant cutaneous malignancies converted to mTORi were included into the study. The control group consisted of eighteen patients maintained on immunosuppressive regimens without mTORi. The level of Tregs with a phenotype defined as CD4lowCD25high was measured before, and 6 months after, mTORi introduction.

Results: In all cases, 6 months after conversion, a significant decrease in the ratio of $C D 4^{+} C D 25^{+}$to $C D 4^{\text {low }} C D 25^{\text {high }}$ from 6.52 to 4.29 was detected $(p=0.035)$. One patient converted to mTORi developed subsequent skin cancer, while in the control group, subsequent skin cancer was recognized in eight patients. Moreover, introducing mTORi significantly improved progression-free survival in this group of patients $(p=0.016)$.

Conclusions: Introducing mTORi to the immunosuppressive regimen resulted in an increase in the number of regulatory cells without increasing the incidence of secondary skin cancer in the investigated group of patients.
\end{abstract}

Key words: skin cancer, kidney transplant recipients, immunosuppression, regulatory T cells.

\section{Introduction}

Patients after organ transplantation are at a higher risk of developing different malignancies compared to the general population. Skin neoplasms are the commonest among them. It is estimated that the prevalence of developing non-melanoma skin cancer (NMSC) in this group of patients is 6 to 200 -fold higher than in the general population [1]. Immunosuppression, viral infection, sunlight, time after transplantation and older age at the moment of transplantation, are the main risk factors [2].

Immunosuppressive therapy always follows allogenic transplantation and is necessary for the maintenance of the graft's function. Tolerance towards alloantigens in organ transplant recipients (OTRs) can be established either by cytotoxic cells activity inhibition, or by stimulation of regulatory T cells (Tregs). However, the high activity of regulatory lymphocytes can lead to such complications as opportunistic infections and malignancies [3-5].

Drugs used in immunosuppressive regimens after organ transplantation inhibit the immune system in different ways; calcineurin inhibitors (CNIs) deeply decrease both cytotoxic and regulatory cells, while the mammalian target of rapamycin inhibitors (mTORi) suppresses the regulatory activity to a lower extent. It has been noticed

Address for correspondence: Agnieszka Cegielska, Department of Nephrology, Transplantology and Internal Diseases, Medical University of Gdansk, 7 Dębinki St, 80-211 Gdansk, Poland, phone: +48 691751 071, fax: +48 583 491 186, e-mail: aggah@wp.pl Received: 5.06.2017, accepted: 23.07.2017. 
that the incidence of MNSC, especially squamous cell carcinoma (SCC) in patients treated with CNIs is higher than in those who are treated with mTORi $[6,7]$.

\section{Aim}

In our study we investigated the quantitative changes in Tregs in peripheral blood of OTRs with post-transplantation skin neoplasm after conversion to MTOR inhibitors (mTORi) and the incidence of secondary skin cancer in that group of patients.

\section{Material and methods}

\section{Patients}

Fourteen cadaver kidney recipients (11 males, 3 females) aged on average 59.7 (range: 40-73) years, after on average 10.5 (range: 2-19) years since transplantation were diagnosed with skin neoplasm, and due to this fact they have been converted to mTORi. Seven patients were diagnosed with single basal cell carcinoma (BCC), 2 patients with single SCC and 1 with melanoma. Four patients presented recurrent NMSC, usually both types. The histological diagnosis of skin malignancies was performed after surgical excision. Patients with autoimmune and inflammatory diseases were not included into the study.

In 6 cases, azathioprine (Aza) was converted to everolimus, in 4 cases CNI was converted to everolimus, in 3 cases mycophenolate mofetil (MMF) was converted to everolimus, and in 1 case Aza was converted to sirolimus.

The blood samples were taken before and 6 months after conversion. During this period of time patients remained stable. Neither exacerbation of the chronic disease nor acute disorder was noted at the time of blood sample collection.

The control group for clinical evaluation consisted of eighteen OTRs aged on average 61 (range: 38-72) years, after on average 10 (range: 3-19) years after transplantation, who were diagnosed with skin cancer in 2010-2014 (years of conversion in the investigated group). Eleven patients developed single BCC, 4 single SCC, 3 developed multifocal skin cancers, among them 1 - both types of NMSC. Neither of patients had more than three lesions. Those patients, after skin cancer diagnosis were maintained on currently-used immunosuppressive therapy. Twelve patients were treated with corticosteroids, CNI and MMF, three patients with CNI and MMF and three patients with corticosteroids, $\mathrm{CNI}$ and Aza.

\section{Lymphocyte phenotyping}

Five milliliters of venous peripheral blood from patients was collected in EDTA-coated tubes. Blood samples of $50 \mathrm{ml}$ per tube were transferred for staining with monoclonal antibodies and red blood cells (RBCs) lysis. Blood cells were incubated with the following antibodies: FITC-conjugated anti-CD3, RPE-Cy5-conjugated anti-
CD4 or RPE-Cy5-conjugated anti-CD8 (DAKO, Denmark) and PE-conjugated anti-CD25 (BD-Pharmingen, USA) for 30 min at $4^{\circ} \mathrm{C}$. After antibody staining, RBCs were lysed with a buffer containing $0.8 \% \mathrm{NH}_{4} \mathrm{Cl}$ and $0.1 \% \mathrm{KHCO}_{3}$. Finally, cells were re-suspended in $200 \mathrm{ml}$ of phosphatebuffered saline (PBS) analyzed with flow cytometry using FACScan instrument (Becton Dickinson, USA).

\section{Analysis}

The obtained FCS data were analyzed with Cyflogic, version 1.2.1 (CyFlo Ltd, Finland). T cells were selected on the basis of their forward and side scatter characteristics and CD3, CD4 and CD8 expression. T regulatory cells were identified based on the expression of CD4 and CD25 antigens. According to Bryl et al. [8], a significantly low expression of CD4 simultaneous with a high expression of CD25 is a sufficient marker of functional human Tregs. Cells with this phenotype express perforin and granzyme B which allows them to kill effector cells directly. Therefore, we used this phenotypic criterion to analyze proportions of $C D 4^{+} C D 25$ cells (naive T cells), $C D 4^{+} C D 25^{+}$cells (activated T cells) and CD4 ${ }^{\text {low } C D 25} 5^{\text {high }}$ cells (Tregs) within a population of $\mathrm{CD}^{+}$cells in patients.

\section{Statistical analysis}

Statistical analysis was done using the Statistica program, version 12 (StatSoft, Inc. (2014) Statistica (data analysis software system), version 12 . www.statsoft.com). The significance tests were chosen according to data distribution with a level of significance $p<0.05$.

\section{Results}

First, we compared proportions of T lymphocytes in kidney recipients ex vivo before and after conversion to mTORi taking into account percentages of $\mathrm{CD}^{+}$and $\mathrm{CD} 8^{+}$cells. No changes were seen in the percentage of $\mathrm{CD}^{+}$cells and $\mathrm{CD} 4^{+}$ cells after 6 months of treatment with mTORi (Figures 1 B and $C$, respectively). Meanwhile, the percentage of CD8+ cells was significantly increased after 6 months of mTORi administration (Figure $1 \mathrm{D}$ ). In some patients, percentages of CD8+ were similar to the percentages of CD4+ cells during treatment with mTORi (Figure $1 \mathrm{~A}$ ), however the difference in CD4/CD8 ratio has not reached statistical significance; calculated $p$ was 0. 073595 (Figure 1E).

Figure 2 A shows representative analysis of the proportion of $\mathrm{CD}^{+} \mathrm{CD} 25^{-}, \mathrm{CD} 4^{+} \mathrm{CD} 25^{+}$and $\mathrm{CD} 4^{\text {low }} \mathrm{CD} 25^{\text {high }}$ cells within the $\mathrm{CD}^{+}$population in a patient before and after conversion to mTORi. Rhomboid regions were adopted, as suggested by Bryl et al. [8], because of visible overlapping of the lowest CD25 signal level shown by the CD4 low population and the highest one shown by other $\mathrm{CD}^{+}$ cells. Although we have found no significant difference between the percentages of $\mathrm{CD} 4^{+} \mathrm{CD} 25^{-}$or $\mathrm{CD} 4{ }^{+} \mathrm{CD} 25^{+}$ cells after 6 months of mTORi administration (Figures 2 $B$ and $C$, respectively) and the difference in percentages 
A
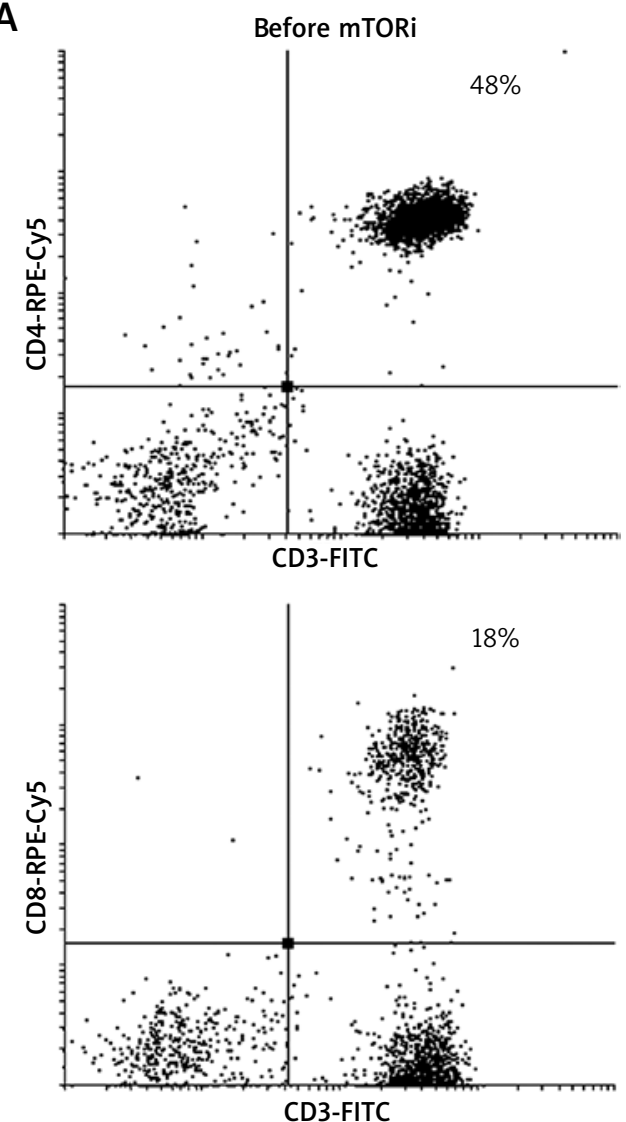

B

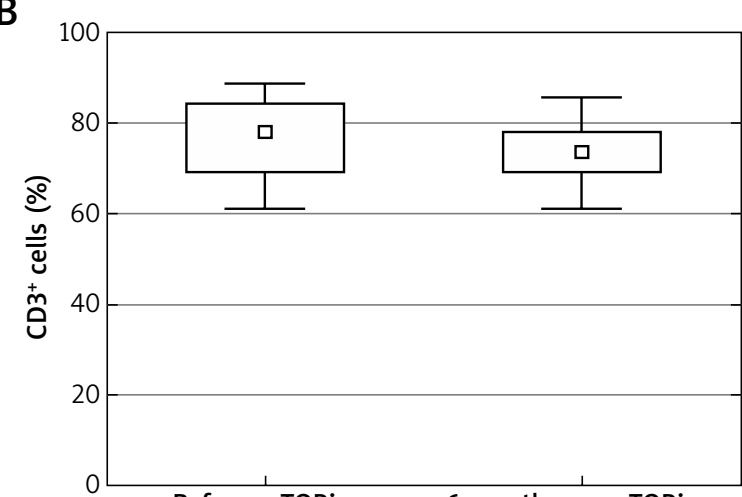

D

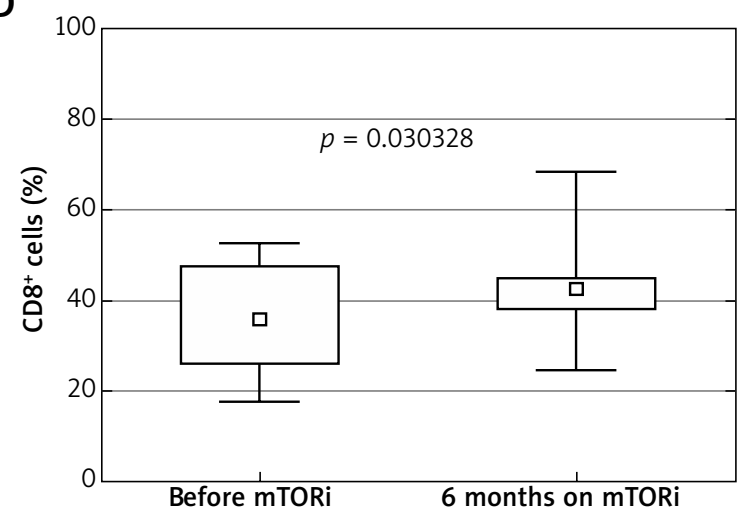

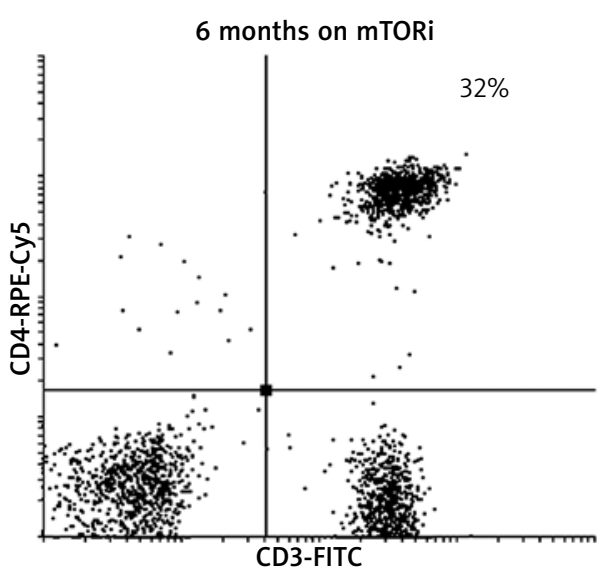

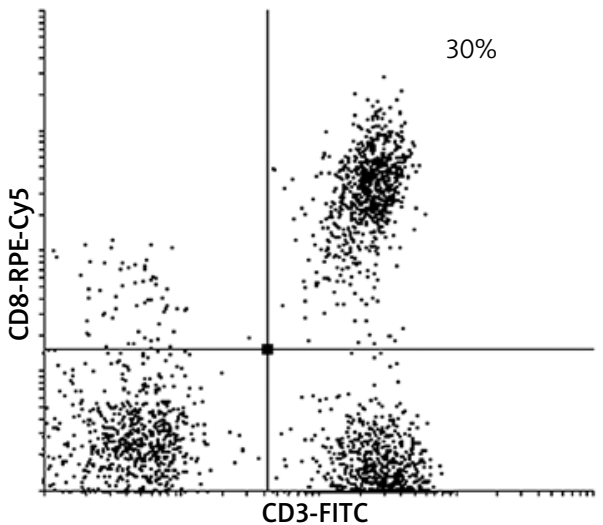

C

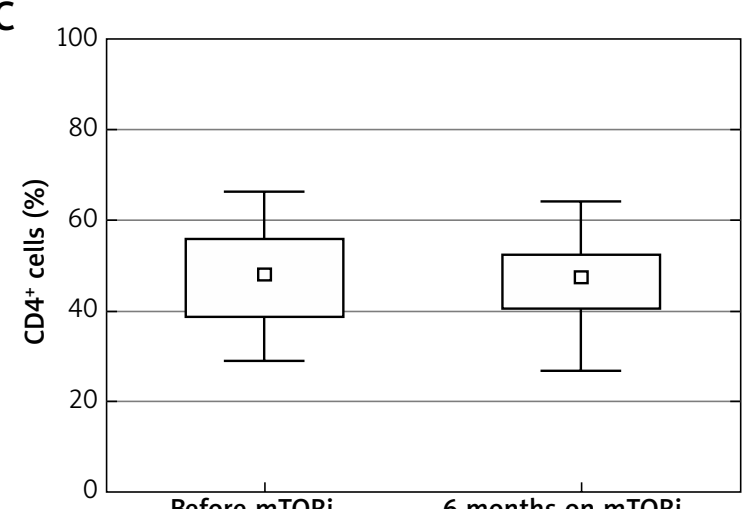

$\mathrm{E}$

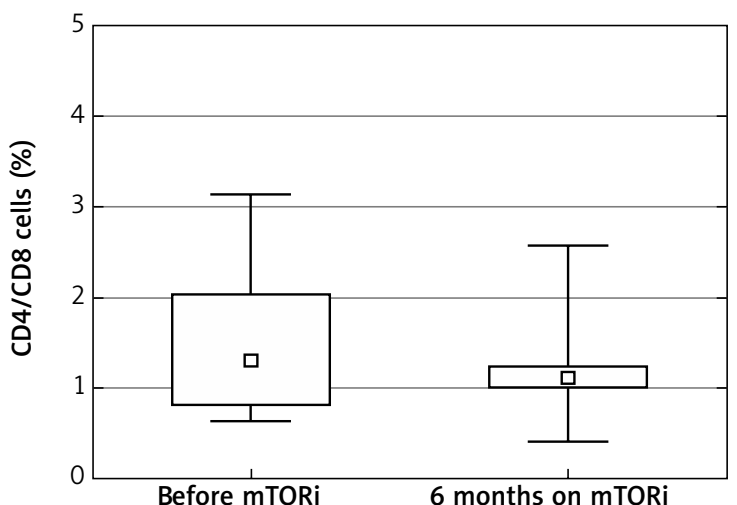

Figure 1. Comparison of percentages of T cells ex vivo. Representative dot-plots (A) show proportions of $C D 3^{+} C D 4^{+}$and $\mathrm{CD} 3^{+} \mathrm{CD} 8^{+}$cells before and after 6 months of therapy with mTORi. Graphs compare percentages of $\mathrm{CD} 3^{+}(\mathrm{B}) \mathrm{CD}^{+} \mathrm{CD} 4^{+}$ (C), $\mathrm{CD}^{+}{ }^{+} \mathrm{CD} 8^{+}$cells $(\mathrm{D})$ and $\mathrm{CD} 4 / \mathrm{CD} 8$ ratio $(\mathrm{E})$ before and after 6 months of therapy with mTORi. Midpoints of figures present medians, boxes present $25^{\text {th }}-75^{\text {th }}$ percentiles and whiskers present the minimum and maximum values observed, Wilcoxon test, $p<0.05$ 
A
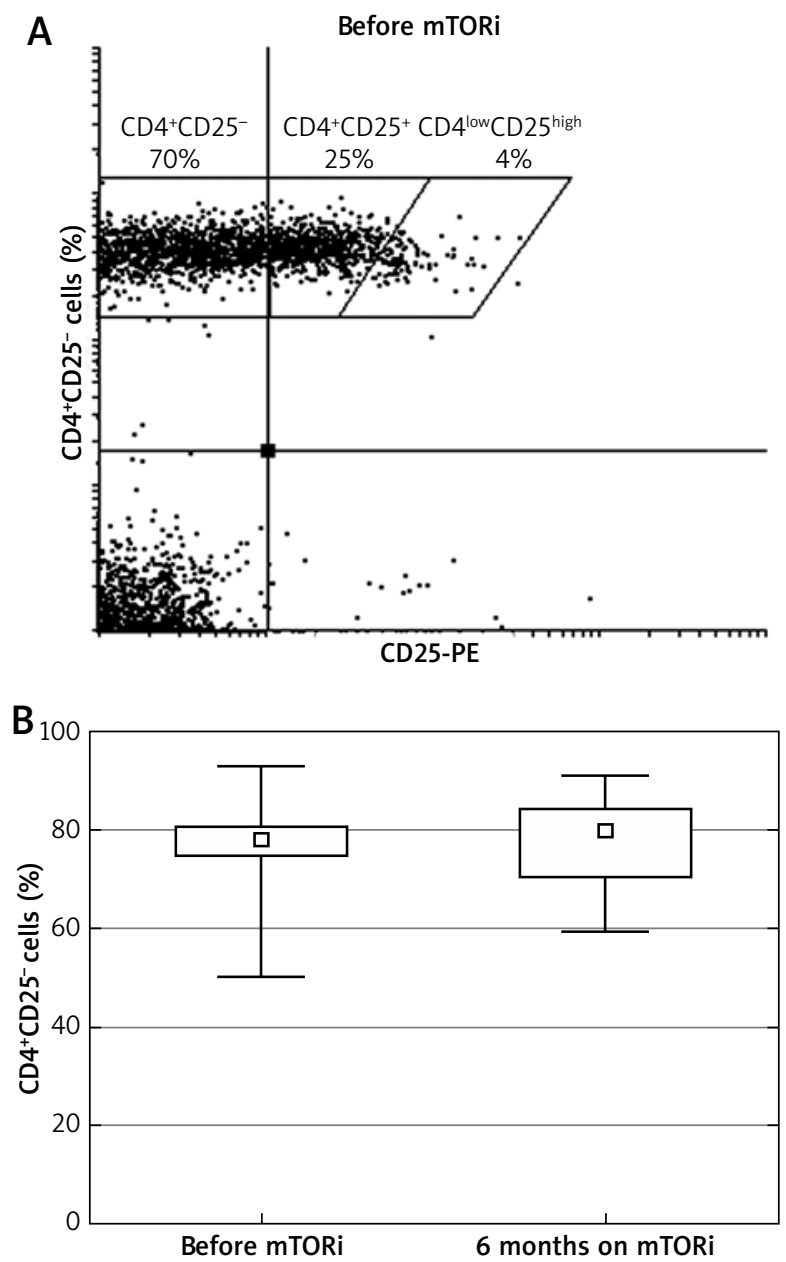

D

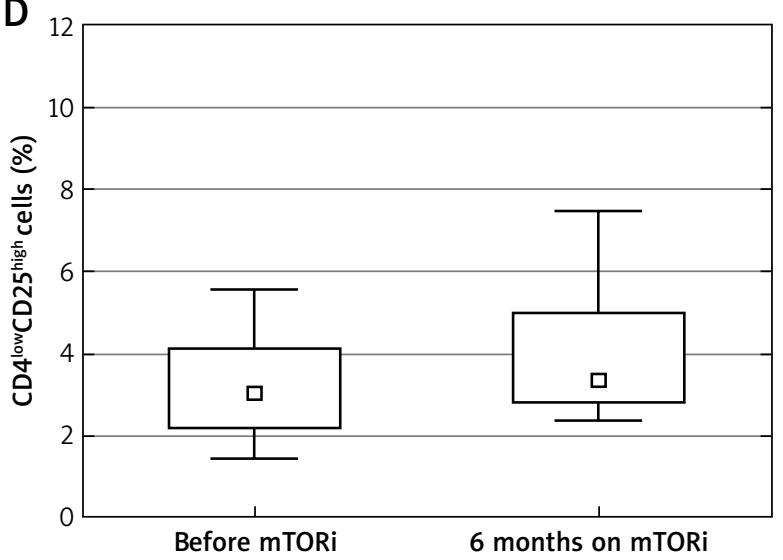

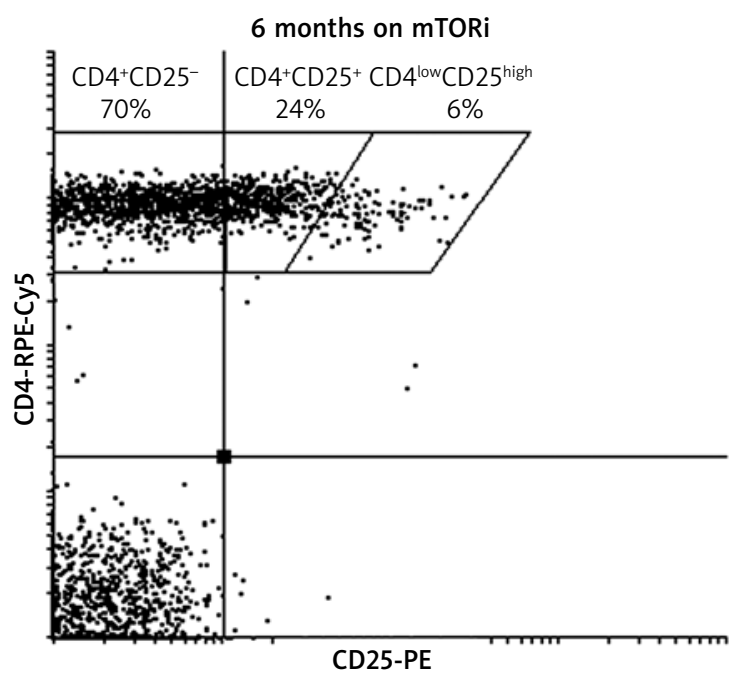

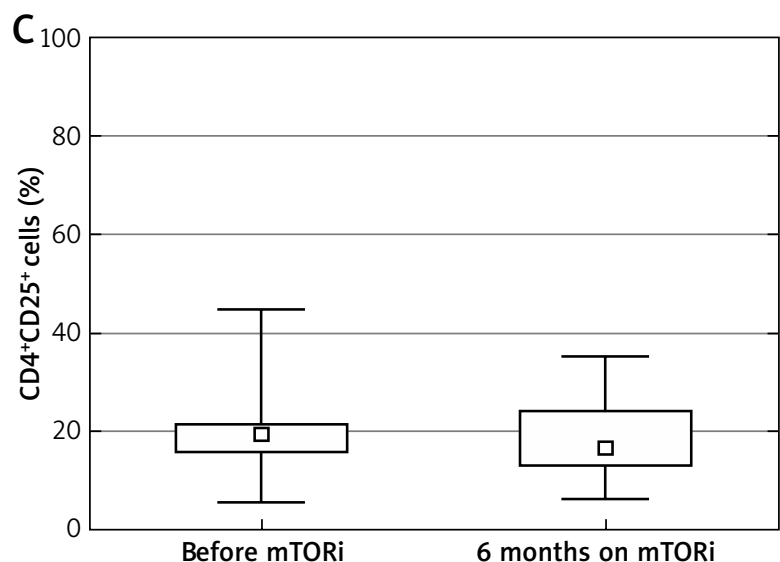

$\mathrm{E}$

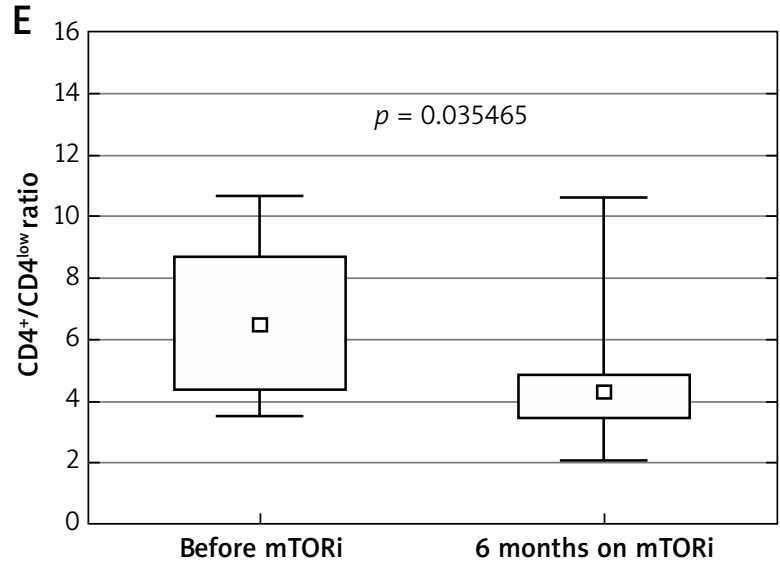

Figure 2. Comparison of activated and regulatory T cells within $C D 4^{+}$population ex vivo. T regulatory cells were identified based on a low expression of CD4 simultaneously with a high expression of CD25. Representative dot-plots (A) show proportions of $C D 4^{+} C D 25^{-}, C D 4^{+} C D 25^{+}$and $C D 4^{\text {low }} C D 25^{\text {high }}$ cells before and after 6 months of therapy with mTORi. Graphs compare percentages of $\mathrm{CD} 4{ }^{+} \mathrm{CD} 25^{-}(\mathrm{B}) \mathrm{CD} 4^{+} \mathrm{CD} 25^{+}(\mathrm{C})$, CD4 $4^{\text {low }} \mathrm{CD} 25^{\text {high }}$ cells (D) and $\mathrm{CD} 4^{+} \mathrm{CD} 25^{+} / \mathrm{CD} 4^{\text {low }} \mathrm{CD} 25^{\text {high }}$ ratio (E) before and after 6 months of therapy with mTORi. Midpoints of figures present medians, boxes present $25^{\text {th }}-75^{\text {th }}$ percentiles and whiskers present the minimum and maximum values observed, Wilcoxon test, $p<0.05$ 


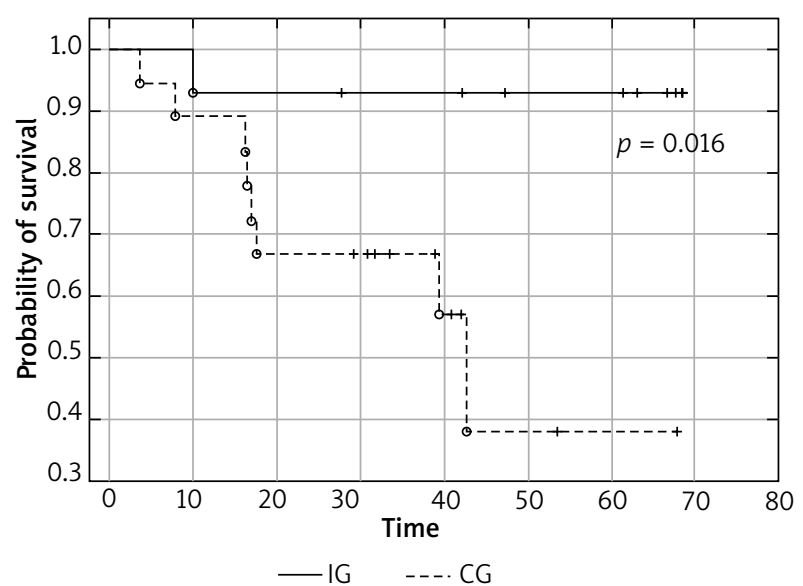

Figure 3. Progression-free survival in the investigated group (IG) and the control group (CG), test log-rank $p<0.05$

of CD ${ }^{\text {low }} C D 25^{\text {high }}$ cells has not reached the level of statistical significance (calculated $p$ was 0.096198), a decrease in the ratio of $\mathrm{CD} 4{ }^{+} \mathrm{CD} 25^{+}$to $\mathrm{CD} 4^{\text {low }} \mathrm{CD} 25^{\text {high }}$ from 6.52 to 4.29 after changing the treatment was observed (Figure 2 E, Table 1).

We have found no correlation between the proportions of different lymphocyte subsets and white blood cell count or lymphocyte count.

In clinical follow-ups, duration from 2 to 6 years, the recurrence of skin neoplastic disease was observed in one patient converted to mTORi, and in 8 patients in whom mTORi were not introduced. The incidence of secondary skin cancer was statistically significant lower in the investigated group than in the control one $\left(\chi^{2}\right.$ test, $p=0.022$ ). Moreover, introducing mTORi to the immunosuppressive regimen significantly improved progressionfree survival in this group of patients (Figure 3).

\section{Discussion}

Long-life immunosuppressive therapy required for graft survival is the main cause of skin complications in solid organ transplant recipients. Organ transplant

Table 1. Percentages of activated and regulatory $T$ cells within $\mathrm{CD}^{+}$population ex vivo

\begin{tabular}{lll}
\hline Variable & $\begin{array}{l}\text { Before mTORi } \\
\text { (median, } \\
\text { min.-max.) }\end{array}$ & $\begin{array}{l}6 \text { months on mTORi } \\
\text { (median, } \\
\text { min.-max.) }\end{array}$ \\
\hline CD4 ${ }^{+}$CD25 $5^{-}$cells $(\%)$ & $78.11,49.90-92.98$ & $80.10,59.42-90.87$ \\
\hline $\mathrm{CD}^{+} \mathrm{CD} 25^{+}$cells $(\%)$ & $19.51,5.58-44.60$ & $16.81,6.41-35.24$ \\
\hline $\begin{array}{l}\mathrm{CD}^{\text {low }} \mathrm{CD} 25^{\text {high }} \text { cells } \\
(\%)\end{array}$ & $3.08,1.44-5.56$ & $3.41,2.38-7.48$ \\
\hline $\mathrm{CD} 4^{+} \mathrm{CD} 25^{+} /$ & $6.52,3.51-10.69$ & $4.29,2.09-10.61$ \\
$\mathrm{CD} 4^{\text {low }} \mathrm{CD} 25^{\text {high }}$ ratio & & \\
\hline
\end{tabular}

recipients with induced immunodeficiency are prone to develop cutaneous infections and skin malignancies. It is estimated that the prevalence of NMSC is higher with each year after transplantation and can reach even up to $80 \%$ twenty years after transplantation [9-11]. Data show that the incidence of skin cancer is higher in cyclosporine- and Aza-treated renal allograft recipients than in those treated with newer agents such as MMF, tacrolimus and sirolimus [12-14]. Carcinogenesis not only results from the drug immunosuppressive activity but also from its direct mutagenic impact on cells.

mTOR inhibitors are the newest group of agents used in immunosuppressive regimens after solid organ transplantation. They inhibit mTOR signaling pathway by downregulation of p7056 kinase activity, what arrests the cell cycle in G1 phase. They seem to be a very promising option for renal transplant recipients due to their low nephrotoxicity, antifibrotic and vascular protective properties, and what is the most important, some anti-cancer properties [15-17]. The latter properties derive from their ability to inhibit cells proliferation and neovascularization $[18,19]$. Recent studies have shown that introduction of mTORi to immunosuppressive regimens reduce the risk of recurrence of skin cancer and conversion from CNI to mTORi is recommended for OTRs with already-recognized skin malignancies [20-23]. De Fijter et al. described 53 kidney transplant recipients with post-transplant NMSC, of which 37 underwent remission after switching CNIs to $m$ TORi [24]. Euvrard et al. in the TUMORAPA study demonstrated that survival time free of subsequent SCC is significantly longer in the patients switched to sirolimus than in the group maintained on CNI [25].

Regulatory cells are a heterogeneous group of lymphocytes, which in healthy individuals limit the immune reactions toward self-antigens. Cells with the phenotype $\mathrm{CD} 4^{+} \mathrm{CD} 25^{\text {high }}$ and expression of the transcription factor FoxP3 was the first described group of lymphocytes with regulatory activity [26]. Further studies revealed that suppressive lymphocytes $C D 8^{+} \mathrm{CD} 28^{-}$also can play a regulatory role [27]. The activity of Tregs prevents allergy and auto-immune disorders in immunocompetent individuals and in organ transplant recipients induce tolerance towards the specific graft antigens. The latter activity could result in reduction of dosage of other agents in individual immunosuppressive regimens, thus lowering the risk of side effects. Nevertheless, it must be remembered that a high number of regulatory cells can result in opportunistic infections and neoplasms [28-30]. Inhibitors of mTORi modulate differently the number and function of circulating Tregs in comparison with CNI. CNIs inhibit FoxP3 expression and suppress Tregs functions, while mTORi preserve the suppressive activity and survival of Tregs [31].

In our study we analyzed the percentage of so-called "natural" Tregs which develop in the thymus. These cells can be identified based on a low CD4 expression simultaneously with a high CD25 expression, as shown by Bryl 
et al. [8]. We chose this type of regulatory lymphocytes as they are most widely described in the literature and the expression of their marker, transcription factor FOXP3, is controlled via mTOR pathway [32]. We have shown that 6 months after mTORi introduction, the proportions of activated T cells (CD4 $\left.{ }^{+} \mathrm{CD} 25^{+}\right)$to Tregs (CD4 $\left.{ }^{\text {low }} \mathrm{CD} 25^{\text {high }}\right)$ decreased from 6.52 to $4.29(p=0.035)$. The same impact on regulatory cells have been observed by San Segundo et al.; 12 months after transplantation, the number of CD4 ${ }^{+}$CD2 $5^{\text {high }}$ FoxP $3+T$ cells was significantly lower in the cyclosporine-treated patient than in rapamycin-treated ones [33]. This tendency has been confirmed in another study; 3 months after conversion from CNIs to mTORi, a significant increase in the absolute number of Tregs was noticed [34]. Carroll et al. has also shown a significant increase in the number of Tregs 6 months after conversion to sirolimus [35]. Hendrikx et al. investigated RTRS who were converted to monotherapy with tacrolimus, rapamycin or MMF [36]. Six months after conversion, a significant increase in circulating CD4+CD25 high FoxP3 $3^{+}$was seen only in the rapamycin group.

In a follow-up of a mean duration of 3.8 years, we observed only 1 case of secondary skin cancer appearance in the investigated group. The subsequent skin malignancy was recognized 15 months after conversion in a patient, who had developed multiple (three) tumors before conversion to mTORi. The incidence of secondary skin neoplasm was statistically significant lower and the progression-free survival was better in the investigated group comparing to the control one.

\section{Conclusions}

We would like to underline that introduction of mTORi to the immunosuppressive regimen increases the level of regulatory cells in peripheral blood in kidney transplant recipients, decreasing the risk of developing skin malignancies at the same time. Furthermore, the induction of the graft specific function of host Tregs may in the future allow reduction of the immunosuppression needed after organ transplantation.

\section{Acknowledgments}

The study was conducted in the Department of $\mathrm{Ne}$ phrology, Transplantology and Internal Medicine, Medical University of Gdansk and in the Department of Pathophysiology, Medical University of Gdansk.

\section{Conflict of interest}

The authors declare no conflict of interest.

\section{References}

1. Jensen P, Hansen S, Moller B. Skin cancer in kidney and heart transplant recipients and different long-term immu- nosuppressive therapy regimens. J Am Acad Dermatol 1999; 40: $177-86$.

2. Danpanich E, Kasiske BL. Risk factors for cancer in renal transplant recipients. Transplantation 1999; 68: 1859-64.

3. Wood KJ, Sakaguchi S. Regulatory T cells in transplantation tolerance. Nat Rev Immunol 2003; 3: 199-210.

4. Hickman SP, Turka LA. Homeostatic T cell proliferation as a barrier to T cell tolerance. Philos Trans R Soc Lond B Biol Sci 2005; 360: 1713-21.

5. Battaglia M. Potential T regulatory cell therapy in transplantation: how far have we come and how far can we go? Transpl Int 2010; 23: 761-70.

6. Marcen R. Immunosuppressive drugs in kidney transplantation: impact on patient survival, and incidence of cardiovascular disease, malignancy and infection. Drugs 2009; 69: 2227-43.

7. Kauffman HM, Cherikh WS, Cheng Y, et al. Maintenance immunosuppression with target-of-rapamycin inhibitors is associated with a reduced incidence of de novo malignancies. Transplantation 2005; 80: 883-9.

8. Bryl E, Daca A, Jówik A, Witkowski JM. Human CD4lowCD25 high regulatory $T$ cells indiscriminately kill autologous activated T cells. Immunology 2009; 128: 287-95.

9. Bouves Bavinck JN, Hardie DR, Green A, et al. The risk of skin cancer in renal transplant recipients in Queensland, Australia. A follow-up study. Transplantation 1996; 61: 715-21.

10. Hartevelt MM, Bavinck JN, Kootte AM, et al. Incidence of skin cancer after renal transplantation in the Netherlands. Transplantation 1990; 49: 506-9.

11. Ramsay HM, Reece SM, Freyer AA, et al. Seven-year prospective study of non-melanoma skin cancer incidence in U.K. renal transplant recipients. Transplantation 2007; 84: 437-9.

12. Bunney MH, Benton EC, Barr BB, et al. The prevalence of skin disorders in renal allograft recipients receiving ciclosporin A compared to those receiving azathioprine. Nephrol Dial Transplant 1990; 5: 379-82.

13. Shuttelworth D, Marks R, Griffin PJ, Salaman JR. Epidermal dysplasia and ciclosporin therapy in renal transplant patients: a comparison with azathioprine. Br J Dermatol 1989; 120: 551-4.

14. Mathew T, Kreis H, Friend P. Two-year incidence of malignancy in sirolimus-treated renal transplant recipients: result from five multicenter studies. Clin Transplant 2004; 18: 446-9.

15. Geissler EK. Can immunosuppressive strategies be used to reduce cancer risk in renal transplant patients? Transplant Proc 2010; 42: S32-5.

16. Monaco A. The role of mTOR inhibitors in management of post-transplant malignancy. Transplantation 2009; 87: 157-63.

17. Mota A, Arias M, Taskinen El, et al. Sirolimus-based therapy following early cyclosporine withdrawal provides significantly improved renal histology and function at 3 years. Am J Transplant 2004; 4: 953-61.

18. Guba M, von Breitenbuch P, Steinbauer M, et al. Rapamycin inhibits primary and metastatic tumor growth by antiangigenesis: involvement of vascular endothelial growth factor. Nat Med 2002; 8: 128-35.

19. Luan FL, Hojo M, Maluccio M, et al. Rapamycin blocks tumor progression: unlinking immunosuppression from antitumor efficacy. Transplantation 2002; 73: 1565-72.

20. Campistol JM, Eris J, Oberbauer R, et al. Sirolimus therapy after early cyclosporine withdrawal reduces the risk for cancer in adult renal transplantation. J Am Soc Nephrol 2005; 17: 581-9. 
21. Diekman F, Campistol JM. Conversion from calcineurin inhibitors to sirolimus in chronic allograft nephropathy: benefits and risks. Nephrol Dial Transplant 2006; 21: 562-8.

22. Fernandez A, Marcen R, Pascual J, et al. Conversion from calcineurin inhibitors to everolimus in kidney transplant recipients with malignant neoplasia. Transplant Proc 2006; 38: 2453-5.

23. Caroti L, Zanazzi N, Paudice N, et al. Conversion from calcineurin inhibitors to everolimus with low-dose cyclosporine in renal transplant recipients with squamous cell carcinoma of the skin. Transplant Proc 2012; 44: 1926-7.

24. De Fijter JW. Use of proliferation signal inhibitors in nonmelanoma skin cancer following renal transplantation. Nephrol Dial Transplant 2007; 22: i23-6.

25. Euvrard S, Morelon E, Rostaing L, et al. Sirolimus and secondary skin cancer prevention in kidney transplant. N Engl J Med 2012; 367: 329-39.

26. Sakaguchi S, Sakaguchi N, Asano M, et al. Immunologic self-tolerance maintained by activated T-cells expressing IL-2 receptor alpha - chains (CD25). Breakdown of a single mechanism of self-tolerance causes various auto-immune diseases. J Immunol 1995; 155: 1151-64.

27. Shevach EM. From vanilla to 28 flavors: multiple varieties of regulatory cells. Immunity 2006; 25: 195-201.

28. Belkaid Y, Rouse BT. Natural regulatory T cells in infectious disease. Nat Immunol 2005; 6: 353-60.

29. Smyth MJ, Teng MW, Swann J, et al. CD4+CD25+ T regulatory cells suppress NK-cell mediated immunotherapy of cancer. J Immunol 2006; 176: 1582-7.

30. Ghiringhelli F, Menard C, Terme M, et al. CD4+CD25+ T regulatory cells inhibit natural killer cell functions in a transforming growth factor-beta - dependent manner. J Exp Med 2005; 202: 1075-108.

31. Dummer CD, Carpio VN, Goncalves LF, et al. FOXP3+ regulatory T cells: from suppression off rejection to induction. Transpl Immunol 2012; 26: 1-10.

32. Sauer S, Bruno L, Hertweck A, et al. T cell receptor signaling controls Foxp3 expression via PI3K, Akt, and mTOR. Proc Natl Acad Sci USA 2008; 105: 7797-802.

33. San Segundo D, Fernandez-Fresnedo G, Ruiz JC, et al. Calcineurin inhibitors, but not rapamycin, reduce percentages of $\mathrm{CD} 4+\mathrm{CD} 25+\mathrm{FOXP3}+$ regulatory T cells in renal transplant recipients. Transplantation 2006; 82: 550-7.

34. San Segundo D, Fernandez-Fresendo G, Gago M, et al. Number of peripheral blood regulatory T cells and lymphocyte activation at 3 months after conversion to MTOR inhibitor therapy. Transplant Proc 2010; 42: 2871-3.

35. Carroll RP, Hester J, Wood KJ, Harden PN. Conversion to sirolimus in kidney transplant recipients with squamous cell cancer and changes in immune phenotype. Nephrol Dial Transplant 2013; 28: 462-5.

36. Hendrikx TK, Velthuis JHL, Klepper M, et al. Monotherapy rapamycin allows an increase of CD4+ CD25high FOXP3+ T cells in renal transplant recipients. Transpl Int 2009; 22: 884-991. 